\title{
Comparação entre as técnicas de amostragem direta em campo e cultura-armadilha para mensuração da diversidade de espécies de fungos micorrízicos arbusculares
}

\author{
Marie Luise Carolina Bartz ${ }^{1}$, Rosilaine Carrenho ${ }^{1,4}$, Sandra Maria Gomes-da-Costa ${ }^{1}$, \\ Arnaldo Colozzi Filho ${ }^{2}$ e Cássio Antonio Tormena ${ }^{3}$
}

Recebido: 17.05.2007; aceito: 03.05.2008

ABSTRACT - (Comparation between field sampling and trap culture techniques for measuring the diversity of arbuscular mycorrhizal fungi). Knowledge of arbuscular mycorrhizal fungi (AMF) communities depends of spores, which may not be available at the moment of collection. The main objective of this paper is the determination of AMF species diversity from direct collection carried out in the field and multiplication in pots. Five soil samples from three areas under no tillage were collected in order to isolate the spores and multiply the AMF in pots. Alfa and beta diversity indexes were used. The spores were extracted from the soil by wet-sieving and centrifugation in sucrose, mounted on semi-permanent slides and identified. In areas I, II and III, 12, 17 and 15 AMF species, respectively, were verified. In the multiplication pots, six species were isolated in area I, 12 in area II and 10 in area III. It was concluded that the survey of AMF diversity is more efficient when the both techniques are associated.

Key words: Glomeromycota, no-tillage, taxonomy

RESUMO - (Comparação entre as técnicas de amostragem direta em campo e cultura-armadilha para mensuração da diversidade de fungos micorrízicos arbusculares). O conhecimento das comunidades de fungos micorrízicos arbusculares (FMA) depende dos esporos, que podem ou não ser recolhidos na coleta. Este trabalho teve como objetivo determinar a diversidade de espécies de FMA a partir do exame de amostras do campo e de culturas-armadilha. Foram coletadas cinco amostras de solo em três áreas, a fim de isolar os esporos e realizar a multiplicação dos FMA em vasos. Os esporos foram extraídos do solo via peneiramento úmido e centrifugação em sacarose, montados em lâminas e identificados. As comunidades de FMA foram avaliadas por meio de índices descritores de alfa e beta diversidade. Nas áreas I, II e III verificaram-se respectivamente 12, 17 e 15 espécies. Nos vasos foram isoladas seis espécies na área I, 12 na área II e 10 na área III. Constatou-se que o levantamento da diversidade de FMA é mais eficiente quando as duas técnicas são associadas.

Palavras-chave: Glomeromycota, plantio direto, taxonomia

\section{Introdução}

Para se realizar estudos de diversidade de fungos micorrízicos arbusculares (FMA), utilizando a taxonomia clássica (morfológica), esporos recolhidos em amostras de solo de uma dada área são avaliados sob microscópio óptico. Muitas vezes esta diversidade é subestimada, pois nem todos os componentes da comunidade estão sob uma forma identificável, ou seja, muitas espécies podem estar presentes somente na forma vegetativa, e as espécies são definidas a partir de características dos esporos. Deste modo, é importante que os objetivos e a forma como os levantamentos de diversidade são conduzidos sejam bem definidos para que se obtenha o máximo de informações sobre a composição real de FMA. Para isto, algumas técnicas de coleta além da simples amostragem pontual, realizada em campo, têm sido utilizadas (Bever et al. 1996, Redecker 2000, Bever et al. 2001).

Propágulos de FMA recolhidos em campo podem ser multiplicados em vasos em associação com plantas micotróficas, em um processo conhecido como iscagem ou cultura-armadilha (Stutz \& Morton 1996).

1. Universidade Estadual de Maringá, Departamento de Biologia, Avenida Colombo 5790, 87020-900 Maringá, PR, Brasil

2. Instituto Agronômico do Paraná, Rodovia Celso Garcia Cid km 375, 86001-970 Londrina, PR, Brasil

3. Universidade Estadual de Maringá, Departamento de Agronomia, Avenida Colombo 5790, 87020-900 Maringá, PR, Brasil

4. Autor para correspondência: rcarrenho@uem.br 
As espécies que produzem esporos nesta condição têm maiores chances de serem identificadas, pois os esporos em geral encontram-se em bom estado de conservação e em várias fases de desenvolvimento. No entanto, fatores como identidade taxonômica e duração do ciclo de vida das plantas hospedeiras, tipo de substrato, espaço físico e número de propágulos dos micobiontes influem diretamente nos resultados relativos à composição de espécies em comunidades de FMA (Ferguson 1981, Biermann \& Linderman 1983, Hetrick \& Bloom 1986, Sieverding 1991, Morton et al. 1993, Bever et al. 2001).

O principal objetivo deste estudo foi comparar as técnicas de levantamento da diversidade de FMA estabelecidas em áreas cultivadas, a partir do exame de amostras trazidas do campo, e de amostras obtidas de cultura-armadilha.

\section{Material e métodos}

Caracterização da área experimental - este estudo foi realizado em três áreas da Fazenda Rhenânia, localizada na região norte do Estado do Paraná no município de Rolândia ( $23^{\circ} 16^{\prime \prime} 30^{\prime}$ 'S e $\left.51^{\circ} 19^{\prime} 45^{\prime \prime} \mathrm{W}\right)$, a uma altitude média de 650 metros. O solo das áreas I e II é do tipo Latossolo Vermelho distroférrico e o da área III é do tipo Nitossolo Vermelho distroférrico, cujos atributos químicos estão discriminados na tabela 1 .

A área I, com aproximadamente 50 hectares, tem sido cultivada há mais de 30 anos sob plantio direto (assim como a área II), e foi cultivada nos últimos anos agrícolas (1997/1998, 1998/1999 e 1999/2000) com soja (verão) e milho-safrinha (inverno). No verão de 2000 e 2001 a área foi cultivada com milho. No período de amostragem do solo (Fev/2001), o milho já havia sido colhido e as plantas tinham sido tombadas há mais ou menos uma semana.

A área II, com aproximadamente 40 hectares, estava ocupada por soja granada em quase toda sua extensão, exceto no meio, onde a soja havia sido replantada e encontrava-se em fase final de floração (verão/2001). A amostragem foi feita nesta região. Nos anos agrícolas de 1997/1998, 1998/1999 e 1999/2000 a área havia sido cultivada com soja, no verão, e milhosafrinha, no inverno.

A área III, com aproximadamente 20 hectares, estava sendo ocupada, no período de amostragem (verão/2001), por milho granado, quase pronto para colheita. Esta área tem um histórico de quinze anos de plantio direto, dez anos de pastagem e dois anos de plantio direto após pastagem. Nos anos agrícolas 1998/1999 e 1999/2000 foram cultivadas soja, no verão, e aveia, no inverno.

Coletas - amostras de solo da rizosfera de cinco plantas, escolhidas ao acaso ao longo das linhas de cultivo em cada uma das áreas, foram coletadas utilizando-se tubos de PVC de $5 \mathrm{~cm}$ de diâmetro x 15 $\mathrm{cm}$ de comprimento. As amostras foram armazenadas, individualmente, em sacos plásticos, previamente identificados. Em laboratório, os sacos foram abertos, para secagem do solo. Cada amostra foi dividida em três porções, uma com $100 \mathrm{~g}$ de solo, para o isolamento dos esporos dos FMA, uma com $50 \mathrm{~g}$, para utilização como inóculo nas culturas-armadilha, e o restante foi enviado para o Laboratório de Análises de Solos da Universidade Estadual de Maringá, para análise dos atributos químicos (tabela 1).

Multiplicação de esporos de FMA em vasos (culturas-armadilha) - foram montados 15 vasos para a multiplicação dos esporos. Cada vaso foi preenchido com $150 \mathrm{~g}$ de substrato estéril (areiasolo 1:1), inoculado com $50 \mathrm{~g}$ do solo rizosférico de interesse e semeado com dez sementes de capim brizantão [Brachiaria brizantha (Hochst.) Stapf.]. Após a germinação e o crescimento das plântulas, realizou-se desbaste, mantendo-se apenas uma planta por vaso. Estas foram mantidas por quatro meses, sob iluminação natural, recebendo aplicações quinzenais

Tabela 1. Atributos químicos do solo das áreas investigadas neste estudo. Área I: milho/milho-safrinha/milho; Área II: soja/milho-safrinha/ soja; Área III: soja/aveia-preta/milho. SB = soma das bases; CTC = capacidade de troca de cátions; V = saturação em bases.

\begin{tabular}{|c|c|c|c|c|c|c|c|c|c|c|c|}
\hline \multirow{2}{*}{ Áreas } & \multirow{2}{*}{$\begin{array}{c}\mathrm{pH} \\
\mathrm{CaCl}_{2}\end{array}$} & \multirow{2}{*}{$\begin{array}{c}\mathrm{C} \\
\mathrm{g} \mathrm{dm}^{-3}\end{array}$} & \multirow{2}{*}{$\begin{array}{c}\mathrm{P} \\
\mathrm{mg} \mathrm{dm}^{-3}\end{array}$} & $\mathrm{Al}$ & $\mathrm{H}+\mathrm{Al}$ & $\mathrm{Ca}$ & $\mathrm{Mg}$ & $\mathrm{K}$ & SB & CTC & \multirow{2}{*}{$\begin{array}{l}\mathrm{V} \\
\%\end{array}$} \\
\hline & & & & \multicolumn{7}{|c|}{$\mathrm{cmol}_{\mathrm{c}} \mathrm{dm}^{-3}$} & \\
\hline I & 5,16 & 26,86 & 31,98 & 0,06 & 5,81 & 6,65 & 1,56 & 0,92 & 9,14 & 14,96 & 60,87 \\
\hline II & 5,62 & 32,11 & 42,30 & 0,00 & 4,42 & 8,93 & 2,85 & 0,57 & 12,37 & 16,79 & 72,91 \\
\hline III & 5,68 & 24,92 & 30,16 & 0,00 & 4,54 & 7,43 & 1,91 & 0,91 & 10,40 & 15,12 & 68,81 \\
\hline
\end{tabular}


de solução nutritiva de Hoagland (sem fósforo) e regas diárias. Ao final deste período, as plantas deixaram de ser regadas por uma semana e, então, realizou-se o corte da parte aérea. O solo presente em cada vaso foi recolhido em saco plástico e uma amostra de $100 \mathrm{~g}$ de solo seco foi retirada para a extração dos esporos.

Isolamento de esporos de FMA - os esporos provenientes do campo e dos vasos de multiplicação foram extraídos do solo a partir do peneiramento por via úmida (Gerdemann \& Nicolson 1963) e da centrifugação em sacarose (Jenkins 1964), depositados em frascos de vidro com água e mantidos sob refrigeração até o momento da montagem das lâminas.

Identificação das espécies de FMA - os esporos isolados de cada amostra foram montados em lâminas semi-permanentes (Morton et al. 1993) e quantificados em microscópio óptico com aumento de 100 vezes. A identificação taxonômica foi feita com base no manual de Schenck \& Pérez (1988), nas descrições fornecidas por Trufem (1988), Carrenho (1994), Carrenho \& Trufem (2001), e acesso ao International Culture Collection of Arbuscular and Vesicular-Arbuscular Mycorrhizal Fungi (http://invam.caf.wvu.edu.).

Avaliação da diversidade nas comunidades de FMA estabelecidas em campo e em vasos - o número de esporos e a freqüência de ocorrência de cada espécie foram determinados a fim de subsidiar o estudo dos índices descritores da alfa diversidade, entropia ou diversidade de Shannon e equabilidade de Pielou, em cada área avaliada. Também foi feita análise comparativa das comunidades de FMA estabelecidas nas duas condições ambientais (campo e vasos), utilizando-se o índice de similaridade de Whittaker $\left(\beta_{\mathrm{W}}\right)$ e a curva de acumulação de espécies, segundo Magurran (1988).

\section{Resultados e Discussão}

Amostragem em campo - pelo exame direto das amostras trazidas do campo foram identificadas 20 espécies, sendo Glomus macrocarpum, G. etunicatum e G. claroideum as mais frequientes e abundantes (tabela 2). Nas áreas I, II e III foram isoladas 12, 17 e 15 espécies, respectivamente. De todas as espécies encontradas, 11 foram comuns às três áreas: Acaulospora laevis, A. mellea, A. scrobiculata, Entrophospora infrequens, Glomus claroideum, G. dimorphicum, G. etunicatum, G. macrocarpum, G. microaggregatum, Gigaspora decipiens e Scutellospora dipurpurescens. Observou-se elevado número de esporos velhos, assim como grande número de espécies com baixo número de esporos e/ou baixa freqüência de ocorrência (tabela 2). O menor número de espécies observado na área I provavelmente está relacionado com a manutenção de uma mesma planta hospedeira (milho) por três cultivos sucessivos, que tende a promover o estabelecimento de associações preferenciais entre algumas espécies de FMA e o fitobionte (Johnson et al. 1991). Nestas condições, em geral, a diversidade de espécies diminui (Menendez et al. 2001, Oehl et al. 2003, Miranda et al. 2005). Podese verificar que embora a riqueza da área I tenha sido menor, a produção de esporos pelas diferentes espécies foi semelhante, o que garantiu alta equabilidade e valor do índice de diversidade próximo ao obtido nas áreas II e III, as quais apresentaram maiores valores de riqueza. Convém salientar que o número de espécies únicas de FMA foi maior na aérea II (5) que nas áreas I (1) e III (1), e isto contribuiu para os maiores valores de riqueza e de diversidade. Segundo Colwell \& Coddington (1994), existe uma tendência da riqueza de espécies declinar das áreas mais perturbadas para as mais conservadas. Neste estudo, a variabilidade e $o$ distanciamento genético das plantas cultivadas na área II (milho e soja), parecem ter perturbado o ambiente rizosférico, em oposição ao verificado nas áreas III (milho e aveia) e I (milho-milho).

Amostragem em vasos - nas culturas-armadilha foram verificadas 14 espécies de FMA (tabela 2), sendo que somente algumas (Appendicispora appendicula, Acaulospora sp., A. morrowiae, Glomus claroideum e G. geosporum) esporularam na rizosfera da planta hospedeira (capim brizantão). Destas, Acaulospora sp. foi a mais abundante, compreendendo cerca de $80 \%$ do número total de esporos (tabela 2). As outras espécies estavam representadas por esporos residuais, provenientes do inóculo. Nesta condição a diversidade foi baixa e as espécies apresentaram padrões de esporulação variados, indicando diferenças na utilização do espaço (McLauhlin \& Roughgarden 1993).

Nos vasos com solo-inóculo da área I, registrou-se a ocorrência de seis espécies de FMA, nos vasos da área II obteve-se 12, e nos da área III, 10 espécies. A maior riqueza de espécies verificada nos vasos da área II pode estar relacionada com o elevado número de esporos (tabela 2) presente na rizosfera das plantas de soja, o que aumenta a probabilidade de contato entre esses propágulos fúngicos e as raízes, possibilitando a colonização dos hospedeiros.

Constatou-se que, nos vasos, o valor da diversidade (entropia de Shannon) foi maior nos solos oriundos 
de áreas onde houve mudança da planta hospedeira, similarmente ao verificado em campo. Com relação à representatividade das espécies de FMA dentro das comunidades, verificou-se que a acentuada competição assimétrica, imposta por Acaulospora sp., comprometeu a performance das outras espécies presentes no inóculo. Ainda assim, pode-se verificar que o solo retirado da área que havia sido cultivada com aveia em rotação (Área III) permitiu o estabelecimento de comunidades mais uniformes, na cultura armadilha. A alternância de gramíneas com estratégias fotossintéticas diferenciadas pode ter estimulado a expressão de espécies de FMA menos competitivas em campo ( $G$. claroideum e Glomus sp., por exemplo), diminuindo as diferenças na abundância de esporos destas populações, mecanismo conhecido como compensação de densidade (May 1979, Tilman 1996).
Comparação das técnicas de levantamento de diversidade - as comunidades de FMA estabelecidas nas áreas de cultivo em campo e nos vasos de multiplicação foram diferentes, apesar destas serem formadas a partir de uma mesma base de propágulos (tabela 2).

Em campo, a introdução de espécies estabelecidas nos arredores e a ocorrência de estresses culturais periódicos e de baixo grau de perturbação favoreceram a diversificação das comunidades de FMA, enquanto nos vasos, o espaço é finito, restringindo a colonização e a esporulação de todas as espécies presentes no inóculo. Com a modificação do ambiente (campovaso) e a limitação do crescimento de ambos os participantes MA, a competição aumenta e segundo Cornell (1993), as comunidades que se estabelecem não são interativas, ou seja, são formadas por populações que não atuam no sistema de forma coletiva. Além

Tabela 2. Avaliação quantitativa das comunidades de fungos micorrízicos arbusculares em áreas cultivadas sob plantio direto a partir do recolhimento direto de esporos em campo e em cultura-armadilha (vasos) ${ }^{1}$.

\begin{tabular}{|c|c|c|c|c|c|c|}
\hline \multirow[t]{2}{*}{ Espécies de FMA } & \multicolumn{2}{|c|}{$\begin{array}{c}\text { Área I }^{2} \\
\left(\beta_{\mathrm{W}}=0,44\right)^{3}\end{array}$} & \multicolumn{2}{|c|}{$\begin{array}{c}\text { Área II }{ }^{2} \\
\left(\beta_{\mathrm{W}}=0,55\right)^{3}\end{array}$} & \multicolumn{2}{|c|}{$\begin{array}{c}\text { Área III }{ }^{2} \\
\left(\beta_{\mathrm{W}}=0,64\right)^{3}\end{array}$} \\
\hline & Campo & Vasos & Campo & Vasos & Campo & Vasos \\
\hline Acaulospora laevis & $10(3)^{4}$ & - & $4(1)$ & - & $2(1)$ & - \\
\hline A. mellea & $65(4)$ & - & $45(4)$ & - & $32(1)$ & $8(2)$ \\
\hline A. morrowiae & - & $5(2)$ & - & $167(3)$ & - & $81(3)$ \\
\hline A. scrobiculata & $32(3)$ & $10(3)$ & $23(5)$ & $12(4)$ & $26(4)$ & $2(1)$ \\
\hline A. tuberculata & - & - & $1(1)$ & - & - & - \\
\hline Acaulospora sp. & - & $774(5)$ & $67(5)$ & $3245(5)$ & $96(5)$ & $1346(5)$ \\
\hline Appendicispora appendicula & - & - & - & $12(2)$ & - & - \\
\hline Entrophospora infrequens & $15(4)$ & - & $13(3)$ & - & $13(4)$ & - \\
\hline Glomus aggregatum & - & - & $24(4)$ & - & - & - \\
\hline G. claroideum & $35(5)$ & - & $166(5)$ & $47(2)$ & $11(3)$ & $131(4)$ \\
\hline G. diaphanum & - & - & - & $16(2)$ & $15(2)$ & $18(3)$ \\
\hline G. dimorphicum & $13(5)$ & $28(3)$ & $74(4)$ & $60(4)$ & $50(5)$ & $67(3)$ \\
\hline G. etunicatum & $83(5)$ & $10(3)$ & $88(4)$ & $53(3)$ & $109(5)$ & - \\
\hline G. geosporum & - & - & $79(3)$ & $2(1)$ & $1(1)$ & - \\
\hline G. macrocarpum & $152(5)$ & $59(5)$ & $288(5)$ & $76(5)$ & $93(5)$ & $87(5)$ \\
\hline G. microaggregatum & $22(2)$ & - & $11(2)$ & $7(1)$ & $27(3)$ & - \\
\hline G. microcarpum & - & - & $59(4)$ & - & - & - \\
\hline G. monosporum & - & - & - & - & $1(1)$ & - \\
\hline G. sinuosum & - & - & $50(1)$ & - & - & - \\
\hline Glomus sp. & - & - & - & $70(3)$ & - & $48(2)$ \\
\hline Gigaspora decipiens & $79(5)$ & - & $20(5)$ & - & $5(2)$ & $1(1)$ \\
\hline Scutellospora coralloidea & $5(1)$ & - & - & - & & - \\
\hline S. dipurpurescens & $1(1)$ & - & $1(1)$ & - & $24(3)$ & - \\
\hline Número total de esporos & 512 & 886 & 1013 & 3767 & 505 & 1789 \\
\hline Riqueza de espécies & 12 & 6 & 17 & 12 & 15 & 10 \\
\hline Diversidade de Shannon & 2,03 & 0,54 & 2,23 & 0,68 & 2,19 & 0,58 \\
\hline Equabilidade de Pielou & 0,77 & 0,20 & 0,75 & 0,22 & 0,77 & 0,35 \\
\hline
\end{tabular}

${ }^{1}$ número acumulado de esporos em cinco amostras; ${ }^{2}$ Área I: milho/milho-safrinha/milho; Área II: soja/milho-safrinha/soja; Área III: soja/aveia-preta/milho; ${ }^{3}$ índice de similaridade de Whittaker; ${ }^{4}$ valores entre parênteses correspondem à freqüência de ocorrência. 
disso, a exclusão de espécies é reforçada pela super exploração e perda de variação estocástica (Ricklefs \& Schluter 1993).

Avaliando-se os dados obtidos nos dois levantamentos (exame direto das amostras de campo e culturas-armadilha) percebe-se que houve detecção de maior número de espécies em cada uma das áreas quando as comunidades de FMA recolhidas nos dois momentos foram consideradas. Na área I, foram isoladas duas espécies nos vasos de multiplicação, que não apareceram no levantamento do material de campo (Acaulospora sp. e A. morrowiae). Na área II, verificou-se a ocorrência de quatro espécies adicionais (Appendicispora appendicula, Acaulospora morrowiae, Glomus sp. e G. diaphanum), e na área III, duas espécies (Acaulospora morrowiae e Glomus sp.) (tabela 2). No entanto, considerando somente os dados obtidos nos vasos de multiplicação, verificou-se detecção de menor número de espécies, nas diferentes áreas (12 vs. 6 na área I, 17 vs. 12 na área II, e 15 vs. 10 na área III). Mudanças da planta hospedeira e das condições de crescimento em experimentos com culturas-armadilha podem causar variações significativas nas populações dos micobiontes (Guo et al. 1993, Bever et al.1996, Bever et al. 2001, Moreira et al. 2007).

Comparando-se as comunidades de FMA estabelecidas em campo e em vasos, percebese que a área I, cultivada sucessivamente com a mesma planta (milho), foi a que apresentou menor similaridade $\left(\beta_{\mathrm{W}}=0,44\right)$, ou seja, menor número de espécies comuns, ocasionando formação de comunidades mais heterogêneas. A rotação com espécies de plantas diferentes (grupos taxonômicos e estratégias fotossintéticas) favoreceu a esporulação de maior número de espécies de FMA, aumentando a diversificação das comunidades em ambas as condições de crescimento (campo e vaso), promovendo a recuperação das espécies nativas do campo, nos vasos de multiplicação. Com isso, as comunidades foram mais homogêneas (tabela 2).

Os dados obtidos neste estudo permitem fazer as seguintes considerações: a) a multiplicação dos FMA em vasos (culturas-armadilha) associada ao levantamento dos esporos recolhidos diretamente do campo possibilita identificar maior número de espécies em trabalhos de diversidade; e b) a cultura-armadilha não deve ser adotada como única metodologia para a determinação da diversidade de espécies.

\section{Literatura citada}

Bever, J.D., Morton J.B., Antonovics, J. \& Schultz, P.A. 1996. Host-dependent sporulation and species diversity of mycorrhizal fungi in a mown grassland. Journal of Ecology 75: 1965-1977.

Bever, J.D., Schultz, P.A., Pringle, A. \& Morton, J.B. 2001. Arbuscular mycorrhizal fungi: more diverse than meets the eye, and the ecological tale of why. Bioscience 51: 923-931.

Biermann, B. \& Linderman, R.G. 1983. Effect of container plant growth medium and fertilizer phosphorus on establishment and host growth response to vesiculararbuscular mycorrhizae. Journal of the American Society for Horticultural Science 108: 962-971.

Carrenho, R. 1994. Efeitos dos fungicidas sistêmicos FosetilAl e Metalaxil-Mancozeb sobre o desenvolvimento de fungos micorrízicos arbusculares naturalmente estabelecidos em rizosferas de Citrus sinensis L. Osbeck/C. limonia L. Dissertação de Mestrado, Universidade Estadual Paulista, Rio Claro.

Carrenho, R. \& Trufem, S.F.B. 2001. Caracterização morfológica de esporos de fungos micorrízicos arbusculares isolados de solo cultivado com milho, na Reserva Biológica e Estação Experimental de MojiGuaçu, São Paulo, Brasil. Hoehnea 28: 191-208.

Colwell, R.K. \& Coddington, A. 1994. Estimating terrestrial biodiversity through extrapolation. Philosophical Transactions of the Royal Society (Series B) 345: 101-18.

Cornell, H. 1993. Unsatured patterns in species assemblages: the role of regional processes in setting local species richness. In: R.E. Ricklefs \& D. Schluter (eds). Species diversity in ecological communities: historical and geographical perspectives. The University of Chicago Press, Chicago, pp. 243-252.

Ferguson, J.J. 1981. Inoculum production and field application of vesicular-arbuscular mycorrhizal fungi. Doctor Thesis, University of California, Riverside.

Gerdemann, J.W. \& Nicolson, T.H. 1963. Spores of mycorrhizal Endogone species extracted from soil by wet sieving and decanting. Transactions of the British Mycological Society 46: 235-246.

Guo, B.Z., An, Z.Q., Hendrix, J.W. \& Dougherty, C.T. 1993. Influence of a change from tall fescue to pearl millet or crabgrass on the mycorrhizal fungal community. Soil Science 155: 393-405.

Hetrick, B.A.D. \& Bloom, J. 1986. The influence of host plant on production and colonization ability of vesicular-arbuscular mycorrhizal spores. Mycologia 78: 32-36.

Jenkins, W.R. 1964. A rapid centrifugal-flotation technique for separating nematodes from soil. Plant Disease Reporter 48: 692. 
Johnson, N.C., Pfleger, F.L., Crookston, R.K., Simmons, S.R. \& Copeland, P.J. 1991. Vesicular-arbuscular mycorrhizas respond to corn and soybean cropping history. New Phytolologist 117: 657-663.

Magurran, A.E. 1988. Ecological diversity and its measurement. Princeton University Press, Princeton.

May, R.M. 1979. The structure and dynamics of ecological communities. In: R.M. Anderson, B.D. Turner \& L.R. Taylor (eds.). Population dynamics. Blackwell Scientific, Oxford, pp. 385-408.

McLaughlin, J. F. \& Roughgarden, J. 1993. Species interactions in space. In: R.E. Ricklefs \& D. Schluter (ed). Species diversity in ecological communities. Historical and geographical perspectives. The University of Chicago Press, Chicago, pp. 89-98.

Menendez, A.B., Scervino, J.M. \& Godeas, A.M. 2001. Arbuscular mycorrhizal populations associated with natural and cultivated vegetation on a site of Buenos Aires province, Argentina. Biology and Fertility of Soils 33: 373-381.

Miranda, J.C.C., Vilela, L. \& Miranda, L.N. 2005. Dynamics and contribution of arbuscular mycorrhiza in culture systems with crop rotation. Pesquisa Agropecuária Brasileira 40: 1005-1014.

Moreira, M., Nogueira, M.A., Tsai, S.M., Gomes-daCosta, S.M. \& Cardoso, E.J.B.N. 2007. Sporulation and diversity of arbuscular mycorrhizal fungi in Brazil Pine in the field and in the greenhouse. Mycorrhiza 17: 519-526.

Morton, J.B., Bentivenga, S.P. \& Wheeler, W.W. 1993. Germ plasm in the International Collection of Arbuscular and Vesicular-Arbuscular Mycorrhizal Fungi (INVAM) and procedures for culture development, documentation and storage. Mycotaxon 48: 491-528.

Oehl, F., Sieverding, E., Ineichen, K., Mäder, P., Boller, T. \& Wienken, A. 2003. Impact of land use intensity on the species diversity of arbuscular mycorrhizal fungi in agroecosystems of Central Europe. Applied and Environmental Microbiology 69: 2816-2824.

Redecker, D. 2000. Specific PCR primers to identify arbuscular mycorrhizal fungi within colonized roots. Mycorrhiza 10: 73-80.

Ricklefs, R.E. \& Schluter, D. 1993. Species diversity: regional and historical influences. In: R.E. Ricklefs \& D. Schluter (eds). Species diversity in ecological communities. Historical and geographical perspectives. The University of Chicago Press, Chicago, pp. 350-363.

Schenck, N.C.\& Pérez, Y. 1988. Manual for identification of VA mycorrhizal fungi. Institute of Food and Agricultural Sciences, University of Florida, Gainesville.

Sieverding, E. 1991. Function of VA mycorrhiza. In: E. Sieverding (ed.). Vesicular-arbuscular mycorrhiza management in tropical agrosystems. Deutsche Gesellschaft fur Technische Zusammenarbeit (GTZ), Eschborn, pp. 57-70.

Stutz, J.C. \& Morton, J.B. 1996. Successive pot cultures reveal high species richness of arbuscular endomycorrhizal fungi in arid ecosystems. Canadian Journal of Botany 74: 1883-1889.

Tilman, D. 1996. Biodiversity: population versus ecosystem stability. Ecology 77: 350-363.

Trufem, S.F.B. 1988. Fungos micorrízicos vesículoarbusculares da Ilha do Cardoso, SP, Brasil. Tese de Doutorado, Universidade de São Paulo, São Paulo. 